A7

doi: 10.14232/ syrpharmacognosy.2021.a7

\title{
Isolation and structure determination of pregnane glycosides and lignans from an African species
}

Reham Hammadi

Email: reham.hammadi@pharmacognosy.hu

Africa has a rich diversity of plants. Recent statistics show that about $25 \%$ of the total number of higher plants in the world is found in Africa [1]. A large amount of the plants is regularly used in traditional medicine; the best-known ones are Aloe ferox, Centella asiatica, Cyclopia genistoides, Harpagophytum procumbens, Hoodia gordonii, Pelargonium sidoides, Prunus africana, and Withania somnifera, among others [1]. The diversity of plants represents a very valuable resource, not only for commercial but also for basic scientific points of view. The aim of our work was the phytochemical and pharmacological investigation of selected African plants. In this experiment, the chloroform extract of the dried plant material (exact botanical identification of the plant is in progress) was separated by the combination of different chromatographic techniques including OCC, VLC, TLC, and HPLC. The structures of the isolated compounds were determined by NMR and MS spectroscopy and comparison with literature data. To date, twelve components, among them eight pregnane glycosides, three lignans and a flavanone were identified. Eight compounds are new natural products. Pregnane glycosides are substituted with three or four sugar moieties (glucose, tevetose, digitoxose and cymarose), joining at $\mathrm{C}-3$ to the pregnane skeleton with $\mathrm{O}$-glycosidic bond. If a glucose molecule occurs in the sugar chain, it can be found at the end of the chain, otherwise tevetose is the last sugar in the chain.

Supervisor: Andrea Vasas

\section{Acknowledgements:}

This work was supported by grants NTP-NFTÖ-19-B-0208, EFOP 3.6.3-VEKOP16-2017-00009, Economic Development and Innovation Operative Programme GINOP-2.3.2-15-2016-00012, GINOP-2.3.2-15-2016-00020, and grant 203913/2018/FEKUSTRAT of the Ministry of Human Capacities.

\section{References}

[1] van Wyk BE. Journal of Ethnopharmacology 2008; 119:342-355. 